\title{
Number of Pelvic Lymph Nodes Examined
}

National Cancer Institute

\section{Source}

National Cancer Institute. Number of Pelvic Lymph Nodes Examined. NCI Thesaurus.

Code C158647.

A request to specify the number of pelvic lymph nodes that were examined. 